Special Issue on Photochemistry, Photophysics and Photobiology

\title{
Modification of fatty acid vesicle using an imidazolium-based surface active ionic liquid: a detailed study on its modified properties using spectroscopy and microscopy techniques ${ }^{\S}$
}

\author{
SHREYA ROY ${ }^{\mathrm{a}}$, SARTHAK MANDAL $^{\mathrm{b}}$, PAVEL BANERJEE $^{\mathrm{a}}$ and NILMONI SARKAR ${ }^{\mathrm{a}, *}$ (D) \\ ${ }^{a}$ Department of Chemistry, Indian Institute of Technology, Kharagpur 721 302, West Bengal, India \\ ${ }^{\mathrm{b}}$ Centre for Innovations in Medicine, Arizona State University, Tempe, United States \\ E-mail: nilmoni@chem.iitkgp.ac.in; nilmonisarkar1208@gmail.com
}

MS received 18 May 2018; revised 9 July 2018; accepted 26 July 2018; published online 17 September 2018

\begin{abstract}
Fatty acid vesicles have attracted views as model protocell membranes in understanding the emergence of life, but their properties can be further modified in the presence of some external molecules. In this work, we have investigated the spontaneous formation of large unilamellar vesicles (LUVs) of oleic acid in aqueous medium in presence of a popular imidazolium-based cationic surface active ionic liquid (SAIL) $\left[\mathrm{C}_{16} \mathrm{mim}\right] \mathrm{Cl}$ and studied the micelle-vesicle transition of aqueous $\left[\mathrm{C}_{16} \mathrm{mim}\right] \mathrm{Cl}$ solution in presence of different molar fractions $(f)$ of oleic acid. This newly formed oleic acid/[ $\left.\mathrm{C}_{16} \mathrm{mim}\right] \mathrm{Cl}$ vesicles exhibit some modified properties compared to the pure fatty acid vesicles. Unlike pure fatty acid vesicles, these vesicles are stable in the $\mathrm{pH}$ range of 2 to 11.2. We have observed the fusion process of these oleic acid/SAIL vesicles to form giant unilamellar vesicles (GUVs) in presence of low concentration of $\mathrm{NaCl}$ solution. To investigate the dynamics of different oleic acid/[ $\left.\mathrm{C}_{16} \mathrm{mim}\right] \mathrm{Cl}$ self-assemblies, we have used fluorescence correlation spectroscopy (FCS). The translational diffusion behavior of three different dyes, Rhodamine 6G, DCM and Pyrromethene 597, which are non-covalently bound to the different regions of the oleic acid/SAIL self-assemblies, have been determined using FCS during the micelle-vesicle transition and upon varying the $\mathrm{pH}$ of the vesicular solution.
\end{abstract}

Keywords. Model membrane; micelle-vesicle transition; single molecule spectroscopy; ionic liquid; fluorescence correlation spectroscopy; fluorescence lifetime imaging microscopy.

\section{Introduction}

In recent years, fatty acid vesicles have drawn great interest as a promising candidate of biomimetic model cell membrane. ${ }^{1-5}$ Fatty acid vesicles can be utilized as drug delivery systems and they are also good carriers of proteins and other bio-macromolecules. ${ }^{6-8}$ They show very interesting features like self-replication, cyclic growth and division of vesicles. ${ }^{9-17}$ That is why it is anticipated that early cell membranes were comprised of fatty acids. So, fatty acids can be used in understanding the emergence of early lives. ${ }^{7,8,10,11}$ Luisi and coworkers have broadly studied a number of other self-replicating systems including micelles and reverse micelles, using various experimental and theoretical model studies. ${ }^{18,19}$

\footnotetext{
*For correspondence

$\S_{\text {Dedicated to Professor M V George on the occasion of his } 90^{\text {th }}}$ Birth Anniversary.
}

It is known that fatty acids spontaneously form vesicles when the $\mathrm{pH}$ of the solution is close to the $\mathrm{pKa}$ value of the corresponding fatty acid. ${ }^{11,12}$ However, these vesicles are stable in a short range of $\mathrm{pH}$. The stability of these vesicles in the aqueous solution depends on the ratio of the fatty acid present in protonated and deprotonated forms. Oleic acid, a well-known fatty acid, forms vesicles near $\mathrm{pH} 8$ (its apparent $\mathrm{pKa}$ value). ${ }^{20}$ Suga et al., have shown different self-assemblies of oleic acid in an aqueous medium with varying the $\mathrm{pH}$ of the medium. ${ }^{21}$ In higher $\mathrm{pH}$, i.e. $\mathrm{pH}>10$, oleic acid molecules get fully deprotonated and get converted into micelles. If the $\mathrm{pH}$ of the solution is more acidic i.e. $\mathrm{pH}<7.5$, then oleic acid forms oil droplets in an aqueous medium. In the range of $\mathrm{pH} 9-10$, vesicular structure and micelles co-exist. The vesicular structure of oleic acid is stable in

Electronic supplementary material: The online version of this article (https://doi.org/10.1007/s12039-018-1532-2) contains supplementary material, which is available to authorized users. 
the range of $\mathrm{pH} 7.8-9 .{ }^{3}$ In this $\mathrm{pH}$ range, the vesicles are formed due to hydrogen bonding interaction between the protonated and deprotonated carboxyl groups of oleic acid molecules. Due to this reason, a major problem of pure fatty acid membranes is that they are highly permeable to protons and unable to maintain the $\mathrm{pH}$ gradient. ${ }^{2}$ Thus the application of pure fatty acid vesicles is limited due to their poor stability with respect to the variation of $\mathrm{pH}$, ionic strength, temperature and concentration of the medium. ${ }^{22}$ However, the stability of fatty acid vesicles over a broader $\mathrm{pH}$ range can be obtained in presence of fatty alcohols or fatty acid glycerol ester. ${ }^{23}$ The limiting stability of fatty acid vesicles under several experimental conditions can also be overcome with the help of another cationic amphiphilic molecule, in presence of which fatty acids can spontaneously form vesicle in the aqueous solution of neutral $\mathrm{pH}$ by the strong synergistic interaction between the head groups of the cationic amphiphile and fatty acid.

Here, we have reported the formation of vesicular self-assemblies of oleic acid in aqueous solution in presence of a long alkyl chain containing imidazoliumbased room-temperature ionic liquid (RTIL). These amphiphilic ionic liquids are categorized into a special class of ionic liquid called surface active ionic liquids (SAILs). ${ }^{24,25}$ It is well-known that these imidazoliumbased SAILs exhibit greater surface activity compared to conventional cationic surfactants in aqueous solution. ${ }^{26-31}$ Due to presence of unique properties of both room temperature ionic liquids (RTILs) and conventional surfactants, SAILs have attracted a lot of attention in recent years. It has been reported that highly ordered self-assemblies like vesicles formed by SAILs can exhibit different or even improved templating behavior compared to the common surfactant-assemblies. ${ }^{30,31}$ There are a few studies on SAILs forming vesicles in presence or absence of any other external agents. However, spontaneous vesicle formation of fatty acids in aqueous solution in presence of a SAIL has not been studied earlier. ${ }^{30,31}$ The formation of large unilamellar vesicles (LUVs) of fatty acids in presence of imidazolium-based SAIL is of significance from the biological point of view because these LUVs can be used as a model of a real biological membrane. Hence, here we are interested in the study of oleic acid vesicles in presence of a popular imidazoliumbased SAIL, 1-hexadecyl-3-methyl imidazolium chloride $\left(\left[\mathrm{C}_{16} \mathrm{mim}\right] \mathrm{Cl}\right)$. The detailed characterization for the formation of SAIL, containing fatty acid vesicles has been performed using turbidity measurement, dynamic light scattering (DLS), transmission electron microscopy (TEM), cryogenic transmission electron microscopy (cryo-TEM), atomic force microscopy
(AFM) and fluorescence lifetime imaging microscopy (FLIM). These mixed vesicles exhibit modified properties in the aqueous solutions as they undergo fusion process in presence of a very low concentration of the aqueous $\mathrm{NaCl}$ solution, whereas lipid vesicles and pure fatty acid vesicles do not fuse under the same experimental conditions. Unlike oleic acid/oleate vesicles, these SAIL containing oleic acid/[ $\left.\mathrm{C}_{16} \mathrm{mim}\right] \mathrm{Cl}$ vesicles are stable over a broad range of $\mathrm{pH}$.

Apart from the detailed structural characterization of these modified fatty acid vesicles, we have investigated the interaction and dynamic properties of oleic acid/[ $\left.\mathrm{C}_{16} \mathrm{mim}\right] \mathrm{Cl}$ self-assemblies using fluorescence correlation spectroscopy (FCS). It is a very sensitive spectroscopic technique and FCS study successfully provides insight into the organization and dynamic properties of the self-assemblies. In recent literatures, FCS has been greatly used to study the diffusion coefficient of a molecule in simple solutions as well as in various organized assemblies such as micelles, vesicles and microemulsions at the single molecular level. ${ }^{32-37}$ Studying the translational diffusion of a single molecule in a biological model membrane is fundamentally important for understanding the protein dynamics and transfection of nucleic acids in cells and thus functioning of cells. ${ }^{34-36}$ Several efforts have been made to understand the aggregation behavior of surfactants, polymers, proteins and ionic liquids in aqueous and non-aqueous media using FCS as a potential alternative technique. ${ }^{38-41}$ It has recently been demonstrated that FCS can be used as an efficient tool to determine the size, size distribution and polydispersity of various surfactant assemblies. ${ }^{42-48}$

In this work, we have investigated the diffusion properties of different self-assemblies of oleic acid/ $\left[\mathrm{C}_{16} \mathrm{mim}\right] \mathrm{Cl}$ system such as micelles, large unilamellar vesicles and vesicles with varying $\mathrm{pH}$ using FCS technique. Hence, we have used three different types of fluorophores, Rhodamine 6G (R6G), 4-(dicyanomethylene)-2-methyl-6-(4-dimethylaminostyryl)-4H-pyran (DCM), and an analogue of BODIPY dye called Pyrromethene 597 (PM597). These dyes preferentially located in the different regions of the selfassemblies. We found a significant difference in the translational diffusion coefficients of these encapsulated probe molecules during the spontaneous micelle-vesicle transition in oleic acid/[ $\left.\mathrm{C}_{16} \mathrm{mim}\right] \mathrm{Cl}$ system.

\section{Experimental}

\subsection{Materials used}

Oleic acid was purchased from SRL, India. 1-Hexadecyl3-methyl imidazolium chloride $\left(\left[\mathrm{C}_{16} \mathrm{mim}\right] \mathrm{Cl}\right)$ was obtained 

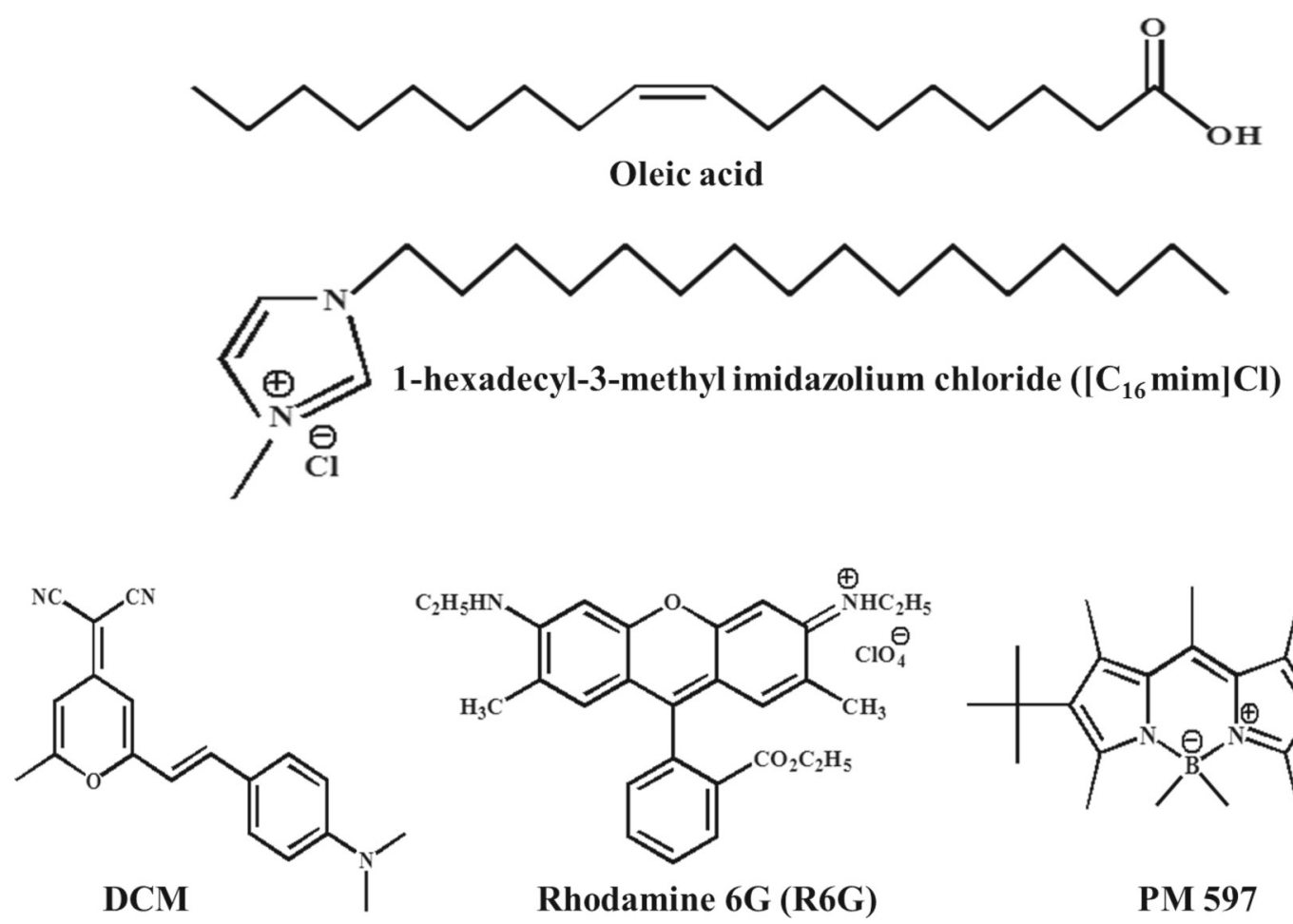

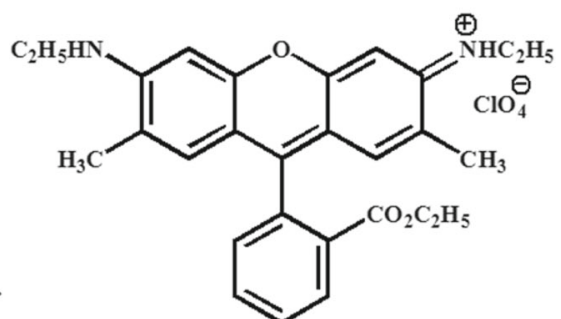

Rhodamine 6G (R6G)

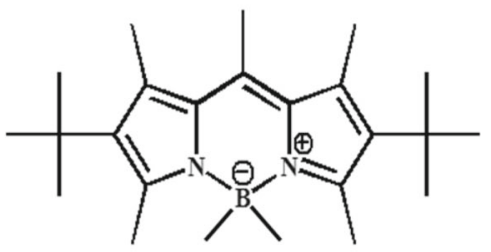

PM 597

Scheme 1. Chemical structures of oleic acid, $\left[\mathrm{C}_{16} \mathrm{mim}\right] \mathrm{Cl}$ and three different fluorophores DCM, R6G and PM597.

from IOLITEC (98\% purity). Both of these chemicals were used without further purification. For the preparation of vesicular solutions, we have used double distilled Milli-Q water. $\mathrm{NaCl}$ was used as received from SRL, India. Rhodamine 6G (R6G, laser grade), 4-(dicyanomethylene)-2-methyl-6(4-dimethylaminostyryl)-4H-pyran (DCM, laser grade) and Pyrromethene 597 (PM597) were used as received from Exciton. The chemical structures of $\left[\mathrm{C}_{16} \mathrm{mim}\right] \mathrm{Cl}$, oleic acid, and fluorescent probe molecules are given in Scheme 1.

\subsection{Preparation of oleic acid/[C $\left.C_{16} \mathrm{mim}\right] \mathrm{Cl}$ self-assemblies}

An appropriate amount of neat oleic acid $(0 \mu \mathrm{L}$ to $30 \mu \mathrm{L})$ was mixed with $2 \mathrm{~mL}$ of $20 \mathrm{mM}$ aqueous solution of [ $\left.\mathrm{C}_{16} \mathrm{mim}\right] \mathrm{Cl}$ to obtain different fractions of fatty acid content in oleic acid/[ $\left.\mathrm{C}_{16} \mathrm{mim}\right] \mathrm{Cl}$ self-assemblies. In absence of oleic acid, the $20 \mathrm{mM}$ aqueous solution of $\left[\mathrm{C}_{16} \mathrm{mim}\right] \mathrm{Cl}$ remains in micellar form. ${ }^{26}$ Now with the increasing amount of oleic acid in the solution, large unilamellar vesicles (LUV) of varying fatty acid content were formed. The molar fraction of fatty acid in oleic acid/SAIL mixed bilayer containing solutions is defined as

$f=\frac{n_{\text {fatty acid }}}{n_{\text {fatty acid }}+n_{\text {SAIL }}}$

where $n$ denotes the number of moles of the component present in the system. Thus the molar fraction of oleic acid was varied from 0 to 0.70 (with respect to the added volume of $0 \mu \mathrm{L}$ to $30 \mu \mathrm{L}$ ) in the oleic acid/SAIL mixed solution. The vesicles were formed spontaneously by mixing the fatty acid into the SAIL solution. The LUVs were converted to small unilamellar vesicles (SUVs) by probe sonication for $15 \mathrm{~min}$ by using an ultrasonic probe sonicator of frequency $\sim 20 \pm 3$ kHz (Processor SONOPROS PR-250 MP, Oscar Ultrasonics Pvt. Ltd. India).

\subsection{Instrumentation}

The characterization of the oleic acid/SAIL self-assemblies in different conditions was performed using absorption spectroscopy, steady-state fluorescence spectroscopy, dynamic light scattering (DLS), transmission electron microscopy (TEM), cryogenic transmission electron microscopy (cryoTEM) and atomic force microscopy (AFM) measurements. Zeta potential measurement was done to understand the mechanism of vesicle fusion in presence of aqueous $\mathrm{NaCl}$ solution. The dynamic properties of the vesicles are characterized by fluorescence correlation spectroscopy (FCS) and fluorescence lifetime imaging microscopy (FLIM). The detailed descriptions of the instruments are discussed in the Supplementary Information.

\section{Results and Discussion}

\subsection{Structural characterization}

3.1a Turbidity study: As stated earlier, oleic acid spontaneously forms vesicles in $\left[\mathrm{C}_{16} \mathrm{mim}\right] \mathrm{Cl}$ solution. With the increasing content of oleic acid in fatty 
(a)

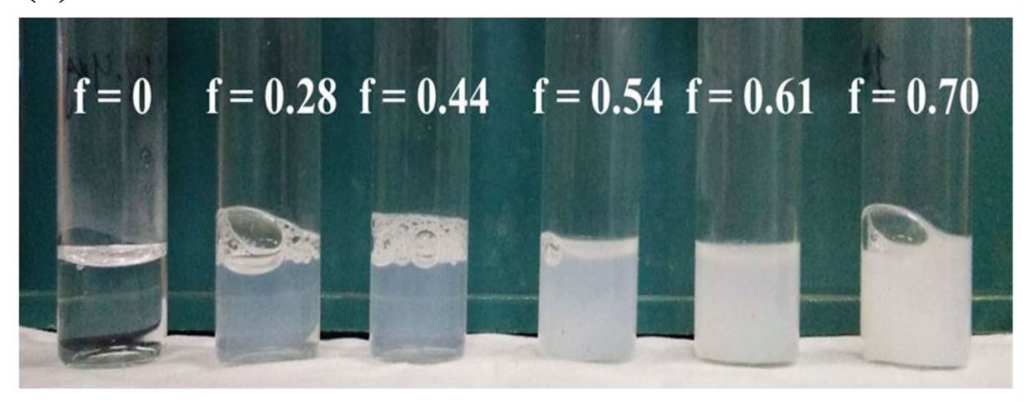

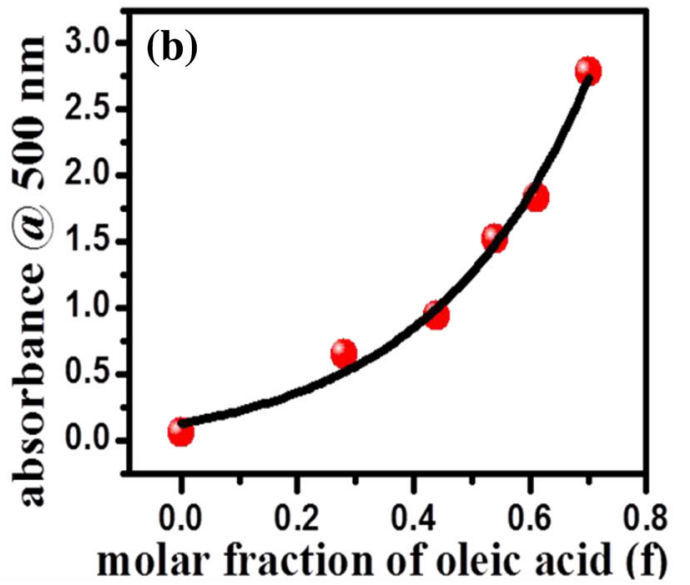

Figure 1. (a) Picture of oleic acid $/\left[\mathrm{C}_{16} \mathrm{mim}\right] \mathrm{Cl}$ solutions with increasing molar fraction $(f)$ of oleic acid, (b) increase in the absorbance of oleic acid/[ $\left.\mathrm{C}_{16} \mathrm{mim}\right] \mathrm{Cl}$ solutions at $500 \mathrm{~nm}$ with increasing molar fraction $(f)$ of oleic acid.

(a)

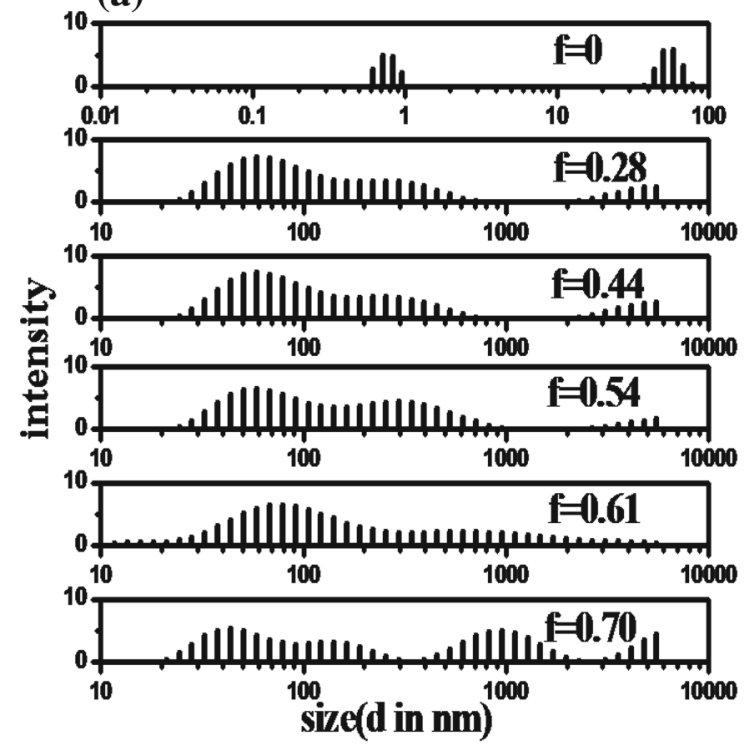

(b)

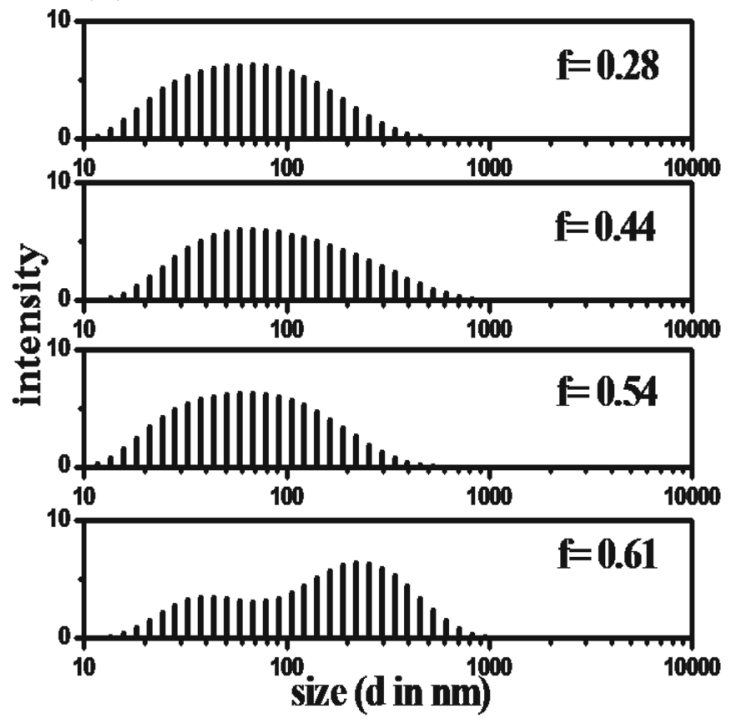

Figure 2. (a) DLS intensity size distribution profiles of aqueous oleic acid $/\left[\mathrm{C}_{16} \mathrm{mim}\right] \mathrm{Cl}$ self-assemblies at different molar fraction $(f)$ of oleic acid, (b) DLS intensity size distribution profiles of aqueous oleic $\mathrm{acid} /\left[\mathrm{C}_{16} \mathrm{mim}\right] \mathrm{Cl}$ self-assemblies at different molar fraction $(f)$ of oleic acid after 15 min probe sonication.

acid/SAIL solutions, turbidity measurement is performed. It is observed that the aqueous solution containing $20 \mathrm{mM}$ of $\left[\mathrm{C}_{16} \mathrm{mim}\right] \mathrm{Cl}$ is becoming more turbid with increasing molar fraction $(f)$ of oleic acid and the picture of the sample solutions is given in Figure 1(a). Figure 1(b) shows the change in absorbance of the oleic acid/ $\left[\mathrm{C}_{16} \mathrm{mim}\right] \mathrm{Cl}$ solution with increasing oleic acid content taken at $500 \mathrm{~nm}$ wavelength. With increasing molar fraction of oleic acid, the gradual increase in the absorbance of the solutions also implies an increase in turbidity of the solutions, which further indicates the formation of vesicles.

3.1b Dynamic light scattering (DLS) study of oleic acid/[ $\left.C_{16} \mathrm{mim}\right] \mathrm{Cl}$ self-assemblies: The change in the size of oleic acid/[ $\left.\mathrm{C}_{16} \mathrm{mim}\right] \mathrm{Cl}$ self-assemblies with the increase in fatty acid content has been investigated using dynamic light scattering (DLS) measurements. Figure 2 shows the size distribution profiles of the solutions at different molar fractions $(f)$ of oleic acid. At $f=0$, the solution contains only $\left[\mathrm{C}_{16} \mathrm{mim}\right] \mathrm{Cl}$, forming spherical micelles which have size $\sim 1 \mathrm{~nm}$. Along with the peak $\sim 1 \mathrm{~nm}$, we have also observed another peak in the size range of $\sim 50$ to $90 \mathrm{~nm}$ which, in all likelihood, arises from the larger aggregates of $\left[\mathrm{C}_{16} \mathrm{mim}\right] \mathrm{Cl}$ as suggested by the earlier reports. ${ }^{31}$ With the addition of oleic acid in the $\left[\mathrm{C}_{16} \mathrm{mim}\right] \mathrm{Cl}$ solution, the micellar aggregates convert into vesicular aggregates which are stable enough and it is confirmed by time-dependent DLS measurements and confocal images (Figures S1 
and S2, Supplementary Information). Thus, the size of the aggregates increases with increasing molar fraction of oleic acid due to the microstructural transition from micelles to vesicles. The aggregation of $\left[\mathrm{C}_{16} \mathrm{mim}\right] \mathrm{Cl}$ forming micelles and conversion of micelles into the vesicular structure in presence of oleic acid can be explained considering the packing parameter. Packing parameter $(\mathrm{S})$ is defined by $\left(\frac{V_{c}}{a_{\mathrm{o}} l_{c}}\right)$, where $V_{c}$ is the hydrocarbon chain volume, $a_{0}$ is the optimal head group area and $l_{c}$ is the chain length of the hydrocarbon. Formation of the micelle is preferred at $S \leq 1 / 3$ whereas vesicle is formed at $0.5 \leq \mathrm{S} \leq 1 .^{49}$ The head group of the SAIL contains imidazolium moiety which is highly hydrated by the water molecules by hydrogen bonding interaction forming a cone-shaped structure. This increases their headgroup area and decreases $\mathrm{S}$ value and thus they form micelles. In presence of oleic acid, there is the possibility of hydrophobic interaction between the hydrocarbon chains of the fatty acid and the SAIL molecules, as well as hydrogen bonding interaction between the carboxylic acid group of oleic acid and the imidazolium part of $\left[\mathrm{C}_{16} \mathrm{mim}\right] \mathrm{Cl}$. Due to these synergic interactions, it is expected that the fatty acid molecule and SAIL molecule together form a compact unit as it is observed in case of $\mathrm{CTAB} /$ cholesterol vesicles reported by Ferrer-Tasies $e t$ $a l .{ }^{50}$ This compact structure has a lower effective headgroup area which increases the packing parameter value and as a result, micelle to vesicle transition occurs with the addition of oleic acid into the $\left[\mathrm{C}_{16} \mathrm{mim}\right] \mathrm{Cl}$ micellar solution. In case of vesicular aggregates for $f=$ 0.28 to $f=0.61$, a broad size distribution pattern is observed having an average hydrodynamic diameter of vesicles $\sim 100 \mathrm{~nm}$, as presented in Figure 2(a). This indicates significant variation in the sizes (polydispersity) of spontaneously formed oleic acid/[ $\left.\mathrm{C}_{16} \mathrm{mim}\right] \mathrm{Cl}$ vesicles due to presence of both small unilamellar vesicles (SUVs) and large unilamellar vesicles (LUVs) in the solutions. At higher concentration of oleic acid ( $f=$ $0.70)$, the population of LUVs significantly increases. The size distribution profiles of oleic acid/[ $\left.\mathrm{C}_{16} \mathrm{mim}\right] \mathrm{Cl}$ solutions are found to be significantly varied upon probe sonication for $15 \mathrm{~min}$. Figure 2(b) shows the DLS intensity size distribution profiles of oleic acid/[ $\left.\mathrm{C}_{16} \mathrm{mim}\right] \mathrm{Cl}$ vesicles as measured after probe sonication of the mixtures at different $f$ values. Probe sonication resulted in the reduction of the size of vesicles and also the broadness of the distribution reduces due to conversion of LUVs into SUVs. ${ }^{31}$ A single peak in the size distribution profile with an average diameter of $80-100 \mathrm{~nm}$ is observed upon sonication of the solutions having the molar fraction of oleic acid up to 0.54 . However, at a very high concentration of oleic acid ( $f=0.61$ and above), the distribution remains broad even after sonication.

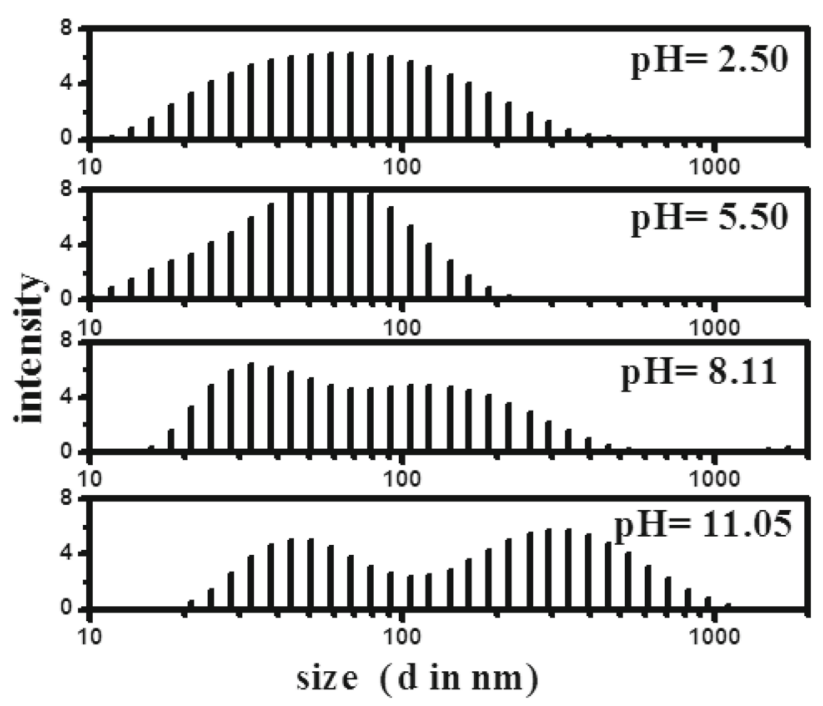

Figure 3. DLS intensity size distribution profile of oleic acid/ $\left[\mathrm{C}_{16} \mathrm{mim}\right] \mathrm{Cl}$ vesicles $(f=0.54)$ in different $\mathrm{pH}$.

\section{1c Effect of $p H$ on oleic acid $/\left[C_{16}\right.$ mim $] C l$} self-assemblies: Fatty acid vesicles are very important as biomimetic model membranes, but these vesicles are stable within a narrow $\mathrm{pH}$ range. For oleic acid/oleate vesicles, this $\mathrm{pH}$ range is $7.8-9 .{ }^{3}$ Here we have investigated the stability of oleic acid/[ $\left.\mathrm{C}_{16} \mathrm{mim}\right] \mathrm{Cl}$ vesicles of $f=0.54$ with varying $\mathrm{pH}$ of the solution and we have observed that these vesicles are stable from $\mathrm{pH}$ 2 to $\mathrm{pH} 11.2$. The $\mathrm{pH}$ of the spontaneously formed oleic acid $/\left[\mathrm{C}_{16} \mathrm{mim}\right] \mathrm{Cl}$ solution (where $f=0.54$ ) was $\sim 2.50$. The probe sonication of the solution resulted in the formation of small unilamellar vesicles of diameter 80-100 nm as confirmed from DLS. The effect of $\mathrm{pH}$ on the DLS intensity-size distribution profile of oleic acid/[ $\left.\mathrm{C}_{16} \mathrm{mim}\right] \mathrm{Cl}$ vesicle has been shown in Figure 3 and it is observed that with increasing $\mathrm{pH}$, size distribution broadened.

In the acidic $\mathrm{pH}$, oleic acid remains in the protonated form. So there is a possibility of hydrogen bond formation between the carboxyl group of oleic acid and the cationic $\left[\mathrm{C}_{16} \mathrm{mim}\right] \mathrm{Cl}$. As we increase the $\mathrm{pH}$ of the solution the carboxyl group tends to deprotonate and the interaction between the SAIL and oleic acid becomes stronger. The broad distribution in the size of the vesicles with increasing the $\mathrm{pH}$ of the solution can be explained in terms of molecular packing parameter (molecular packing parameter (S) is defined previously). ${ }^{49}$ In acidic $\mathrm{pH}$, the vesicle is stabilized by the hydrogen bonding interaction between the cationic SAIL and the carboxylic acid group of oleic acid. However, after increasing the $\mathrm{pH}$ of the solution carboxylic acid group of the oleic acid molecule becomes deprotonated and it strongly interacts with the cationic SAIL via 
electrostatic interaction and that leads to decrease in the effective headgroup area of the vesicle. Thus, the packing parameter of the vesicles increases with increasing the $\mathrm{pH}$ of the medium which leads to decrease the net curvature of the surfactant aggregates. As a result, the corresponding size of the vesicles also increases. Thus the self-aggregation properties of the oleic acid vesicle can be tuned by the addition of the cationic SAIL and the vesicle system is stabilized over a broad $\mathrm{pH}$ range as compared to oleic acid/oleate vesicles.

\section{1d Effect of addition of salt on oleic acid $/\left[C_{16} \mathrm{mim}\right]$} $\mathrm{Cl}$ self-assemblies: Membrane fusion process is very important in cell biology study as it is involved in many biological processes such as cell fusion, cell division, exo and endo-cytosis. ${ }^{51,52}$ In biological cells, membrane fusion happens by the action of some fusion assisting proteins, but this fusion is very specific as it occurs in a single molecular level. Therefore, to understand the fusion mechanism in molecular level, significant efforts have been made using synthetic lipid vesicles under various physicochemical conditions. ${ }^{51-55}$ It is reported that liposomes undergo rapid bilayer fusion in presence of divalent salts. ${ }^{53}$ Kantor and Prestegard have studied the fusion of DMPC vesicles in presence of free fatty acids such as myristic acid. ${ }^{54}$ There are a number of reports on the fusion of phospholipid-based vesicles under different experimental conditions, but the study of fusion process of non-phospholipid based vesicles is few. Henderson and Paxton have demonstrated the fusion of polymer-based large unilamellar vesicles into giant vesicles in presence of dilute aqueous $\mathrm{NaCl}$ solution with agitation. ${ }^{55}$ However, under such conditions, lipid vesicles do not undergo spontaneous fusion. Since fatty acids are an important component of biological cells, the fusion of fatty acid vesicles can be correlated with the membrane fusion of real biological cells. In this work, we have shown that small unilamellar oleic $\mathrm{acid} /\left[\mathrm{C}_{16} \mathrm{mim}\right] \mathrm{Cl}$ vesicles prepared by probe sonication, fuse upon addition of low concentration of aqueous $\mathrm{NaCl}$ solution. Figure 4 shows DLS intensity-size distribution profiles for oleic acid/[ $\left.\mathrm{C}_{16} \mathrm{mim}\right] \mathrm{Cl}$ vesicular system $(f=0.54)$ with increasing concentration of $\mathrm{NaCl}$. As stated earlier that large unilamellar oleic acid/SAIL vesicles are converted into small unilamellar vesicles of $\sim 80$ to $100 \mathrm{~nm}$ size by $15 \mathrm{~min}$ probe sonication and these small vesicles undergo rapid fusion producing giant vesicles in presence of low concentration of $\mathrm{NaCl}$ solution. In presence of aqueous $20 \mathrm{mM} \mathrm{NaCl}$, the size of the vesicles increases to more than $\sim 1000$ $\mathrm{nm}$. However, in addition to the giant vesicles, unfused small sized vesicles are also present in the solutions as observed from DLS results in Figure 4.

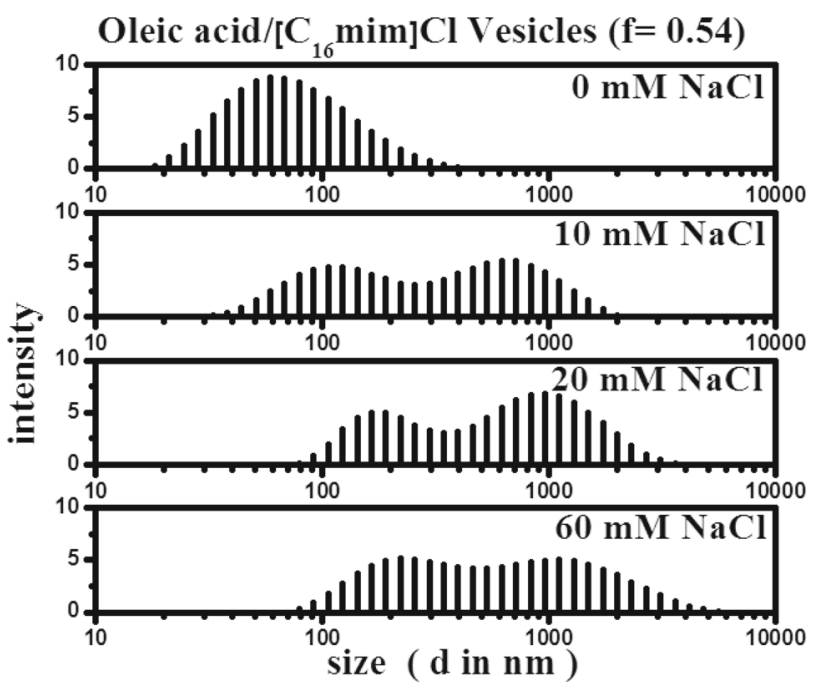

Figure 4. Variation of DLS intensity size distribution profiles of oleic acid/ $\left[\mathrm{C}_{16} \mathrm{mim}\right] \mathrm{Cl}$ vesicles $(f=0.54)$ with increasing concentration of $\mathrm{NaCl}$.

To understand the detailed microstructural feature of the fused vesicles we have recorded the fluorescence lifetime images of oleic acid/[ $\left.\mathrm{C}_{16} \mathrm{mim}\right] \mathrm{Cl}$ vesicles in presence and absence of low concentration of $\mathrm{NaCl}$ as discussed in the latter section. It is important to note that in presence of such a low concentration of $\mathrm{NaCl}$ solution, phospholipid vesicles or pure fatty acid vesicles do not undergo fusion. This has been confirmed by our control experiment (Figure S3, Supplementary Information) and the result matches with the literature reports. ${ }^{55,56}$ Carmona-Ribeiro and Chaimovich earlier demonstrated $\mathrm{NaCl}$ salt-induced fusion of dioctadecyldimethylammonium chloride (DODAC) and sodium dihexadecylphosphate (DHP) forming vesicles. ${ }^{56}$ It is reported by them that in case of phospholipid vesicles like DPPC, the hydration sphere around the vesicle bilayer is more structured due to presence of both the quaternary ammonium and the phosphate groups. This accounts for their greater stability even in presence of low concentration of salt solution. This may imply that in the case of oleic acid $/\left[\mathrm{C}_{16} \mathrm{mim}\right] \mathrm{Cl}$ vesicles, there is loose binding of water molecules around the vesicle bilayer and thus provides less stability of the bilayer as compared to the phospholipid vesicles, in presence of low concentration of $\mathrm{NaCl}$ solution. On the other hand, pure oleic acid vesicles also do not fuse under such condition since in this system the surrounding water is more tightly bound with the head groups in the bilayer.

\section{1e Transmission electron microscopy (TEM) and} atomic force microscopy studies: From the TEM images of oleic acid/SAIL system, the presence of vesicular assemblies is clearly observed. Vesicles of 

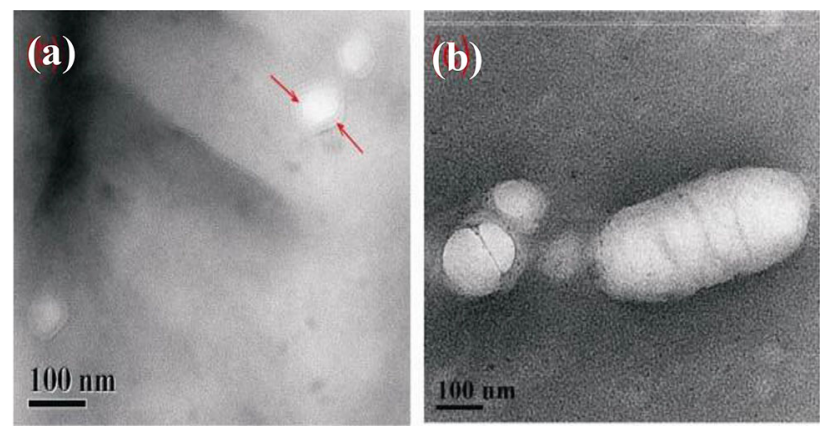

Figure 5. HR-TEM images of (a) oleic acid/[C $\left.\mathrm{C}_{16} \mathrm{mim}\right] \mathrm{Cl}$ vesicles $(f=0.54)$ after $15 \mathrm{~min}$ probe sonication and $(\mathbf{b})$ fusion of oleic acid $/\left[\mathrm{C}_{16} \mathrm{mim}\right] \mathrm{Cl}$ vesicle in presence of $60 \mathrm{mM} \mathrm{NaCl}$ solution.

oleic acid/[ $\left.\mathrm{C}_{16} \mathrm{mim}\right] \mathrm{Cl}$ (obtained after $15 \mathrm{~min}$ probe sonication of the solution of $f=0.54$ ) are clearly observed from the HR-TEM images as shown in Figure 5 and one of the vesicles is shown by the red arrows in Figure 5(a). The fusion of the oleic acid/[ $\left.\mathrm{C}_{16} \mathrm{mim}\right] \mathrm{Cl}$ vesicles in presence of $60 \mathrm{mM} \mathrm{NaCl}$ solution is also being confirmed by the HR-TEM image (Figure 5(b)). From the cryo-TEM images of oleic acid/[ $\left.\mathrm{C}_{16} \mathrm{mim}\right] \mathrm{Cl}$ vesicles of $f=0.54$ (after $15 \mathrm{~min}$ probe sonication), the thickness of the vesicle membrane have been obtained as $\sim 6 \mathrm{~nm}$ (Figure S4, Supplementary Information) and the procedure for cryo-TEM is followed as given in the literature. ${ }^{57}$

AFM images of the oleic acid/[ $\left[\mathrm{C}_{16} \mathrm{mim}\right] \mathrm{Cl}$ vesicle solution $(f=0.54)$ are also obtained (by 10 times dilution and without probe sonication) and it is shown in Figure 6. From the AFM images, the width and height of the vesicles are obtained as $\sim 500$ to $800 \mathrm{~nm}$ and $\sim 100 \mathrm{~nm}$ respectively.

\section{1f Fluorescence lifetime imaging microscopy} (FLIM) studies: FLIM has been extensively used to monitor the changes of various intracellular physiological functions such as, viscosity, $\mathrm{pH}$, and the presence of ions which strongly influence the excited state lifetimes of the embedded fluorophores. ${ }^{58,59}$ While DLS measurements provide the size distribution profiles of the vesicles in solutions, the proper examination of their bilayer structures can only be achieved from microscopic evidence. Therefore, to understand the organization and dynamic behavior of these vesicular assemblies, we have used time-resolved fluorescence lifetime imaging microscopy measurements. Blanchard and coworkers have shown how FLIM can be used as a sensitive tool for understanding the structural deformation of phospholipid vesicles in presence of ethanol and $n$-butanol. ${ }^{60,61}$ In this work, we have studied the lifetime imaging of oleic acid/[ $\left.\mathrm{C}_{16} \mathrm{mim}\right] \mathrm{Cl}$ vesicles using DCM dye. The image presented in Figure 7(a) is the time-domain image of oleic acid/[ $\left.\mathrm{C}_{16} \mathrm{mim}\right] \mathrm{Cl}$ vesicles $(f=0.54)$. The bright coloured regions indicate the dyes encapsulated within the planar bilayer of the vesicular assemblies. As obtained from DLS measurements, here also we observed a variation of sizes of vesicles. It is clearly observed that the vesicles are mainly spherical in nature. Since the objectives used in the confocal microscope have a depth of field significantly higher than the thickness of the bilayer, the detachment of the vesicles from the glass slide support often results in a rapid loss of the signal. Figure 7(b) represents the FLIM image of a fused oleic acid/[ $\left.\mathrm{C}_{16} \mathrm{mim}\right] \mathrm{Cl}$ vesicle $(f=0.54)$ in presence of $20 \mathrm{mM} \mathrm{NaCl}$. We can observe that in presence of $\mathrm{NaCl}$ solution, the size of the vesicles have increased and also it indicates that fusion is taking place. In correlation with the results obtained from DLS measurements, here also we have observed the presence of small-sized unfused vesicles along with the giant vesicles. Figure 7(d) represents FLIM image of a vesicle after fusion has taken place in presence of $60 \mathrm{mM} \mathrm{NaCl}$ solution. The relative stabilities of
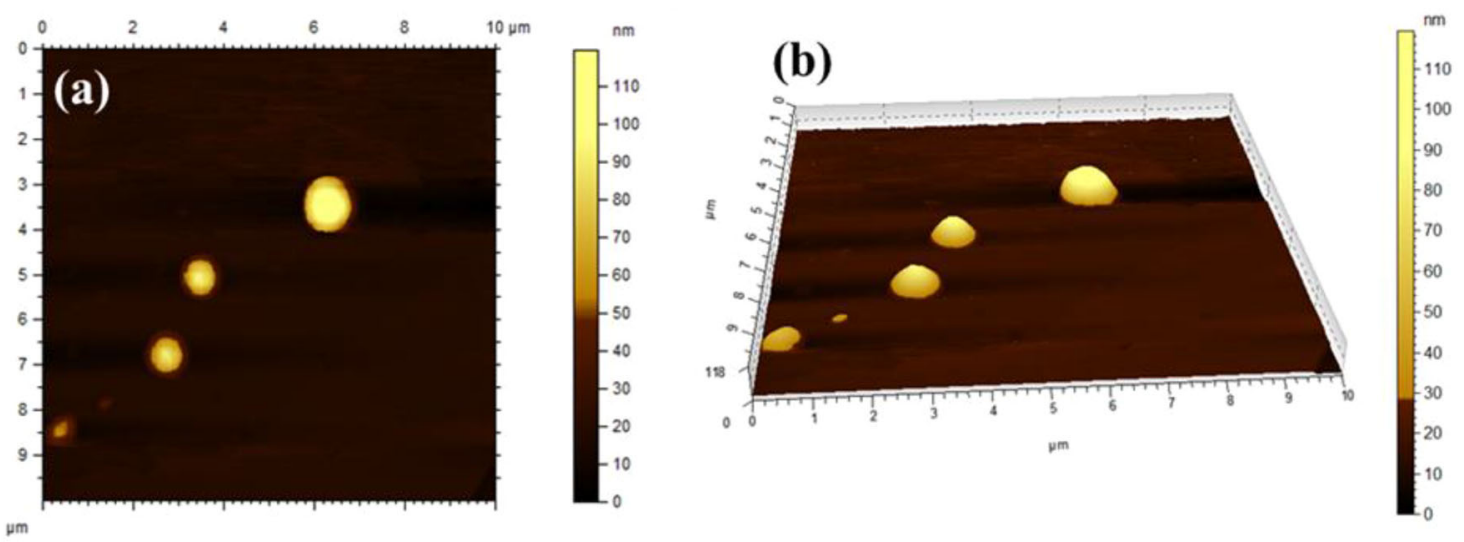

Figure 6. (a) Tapping-mode $\mathrm{AFM}$ image of oleic acid $/\left[\mathrm{C}_{16} \mathrm{mim}\right] \mathrm{Cl}$ vesicles (after 10 times diluting the solution) $(f=0.54)$, (b) the height profile diagram of the vesicles. 

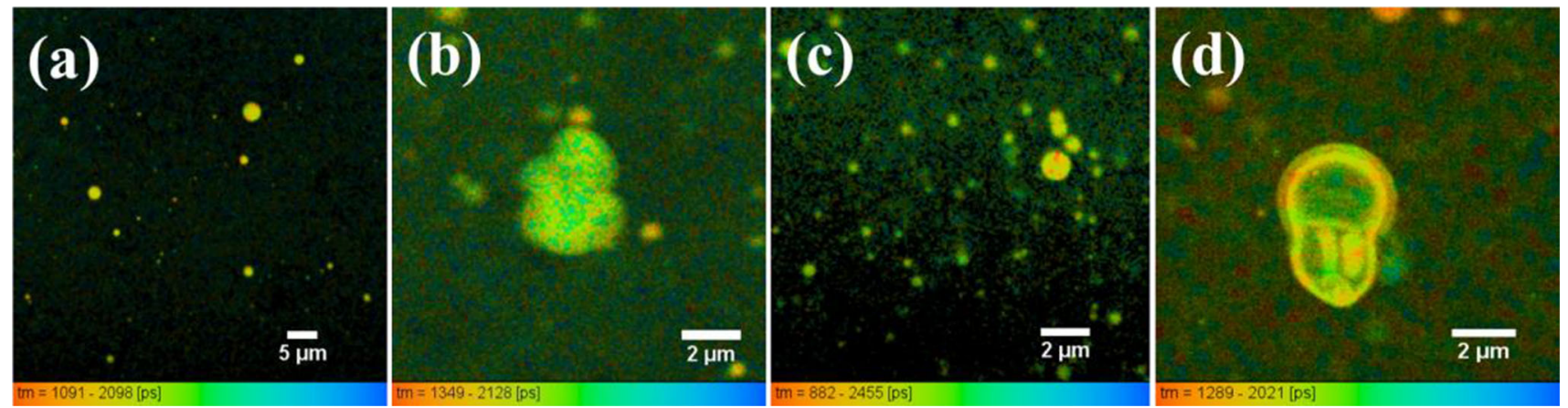

Figure 7. FLIM images of (a) oleic acid $/\left[\mathrm{C}_{16} \mathrm{mim}\right] \mathrm{Cl}$ vesicles $(f=0.54)$ loaded with DCM as membrane-bound probe; (b) a vesicle after fusion has taken place in presence of $20 \mathrm{mM} \mathrm{NaCl}$ solution; (c) oleic acid/[C $\left.\mathrm{C}_{16} \mathrm{mim}\right] \mathrm{Cl}$ vesicles $(f=0.54)$ loaded with DCM in presence of $60 \mathrm{mM} \mathrm{NaCl}$ solution, and (d) a vesicle after fusion has taken place in presence of $60 \mathrm{mM}$ $\mathrm{NaCl}$ solution.

small and large vesicles are dependent on some kind of short-range interactions. Possibly, the short-range hydration repulsive force between the vesicles creates the energy barrier for their fusion. Suga et al., have shown that oleic acid vesicle membrane modified with cationic surfactant DDAB results in a decrease in the hydration of the membrane. ${ }^{62}$ Thus, in our study, we can predict that oleic acid/[ $\left.\mathrm{C}_{16} \mathrm{mim}\right] \mathrm{Cl}$ vesicles have lesser water structure around its surface as compared to pure oleic acid vesicles and as a result, the oleic acid/SAIL vesicles show lower repulsive force at a close approach which facilitates its fusion. Sarkar et al. have also studied the fusion of oleic acid vesicles modified with ethyl amine in presence of aqueous $\mathrm{NaCl}$ solution and have predicted that osmolarity is also an important factor for vesicle fusion. ${ }^{63}$ They have suggested that in a salt solution, the osmotic gradient inside and outside the vesicles results in water movement across the vesicle membrane causing swelling of vesicles which further promotes fusion of vesicle membranes. This osmotic gradient is also present in oleic acid/[ $\left.\mathrm{C}_{16} \mathrm{mim}\right] \mathrm{Cl}$ vesicle system in presence of $\mathrm{NaCl}$ and predicts a similar result. Zeta potential of oleic acid $/\left[\mathrm{C}_{16} \mathrm{mim}\right] \mathrm{Cl}$ vesicles in presence of different concentration of $\mathrm{NaCl}$ solution have been measured (Figure S5, Supplementary Information) and the result shows that electrostatic force also plays an important role in the fusion of vesicles in presence of $\mathrm{NaCl}$ solution. It is observed that oleic acid/ $\left[\mathrm{C}_{16} \mathrm{mim}\right] \mathrm{Cl}$ vesicles have high positive zeta potential and with increasing concentration of $\mathrm{NaCl}$ solution, zeta potential decreases. Thus with increasing $\mathrm{NaCl}$ concentration, the electrostatic repulsive force between the vesicles decreases and the vesicles can approach closer which makes fusion more feasible.

The fusion of this oleic acid/[C $\left.\mathrm{C}_{16} \mathrm{mim}\right] \mathrm{Cl}$ vesicles in presence of $\mathrm{NaCl}$ solution can be visually proved. For this purpose, we have taken oleic acid/ $\left[\mathrm{C}_{16} \mathrm{mim}\right] \mathrm{Cl}$ vesicles loaded with DCM dye in presence of $60 \mathrm{mM} \mathrm{NaCl}$ solution and performed the time series FLIM analysis to obtain confocal images to understand different stages of vesicle fusion. The collection time of each image is $1 \mathrm{~s}$, and the collected images are assembled together and the images are converted into movie frames using software (Movie S1, Supplementary Information).

\subsection{Fluorescence correlation spectroscopy (FCS) studies}

3.2a Micelle-vesicle transition in oleic acid/[ $\left[C_{16}\right.$ mim $] \mathrm{Cl}$ system: In this section, we have investigated the variation of diffusion properties of three different dyes with the spontaneous micelle-vesicle transition in aqueous oleic acid/ $\left[\mathrm{C}_{16} \mathrm{mim}\right] \mathrm{Cl}$ system. Dey et al., have investigated the region dependency of the diffusion coefficient $\left(D_{t}\right)$ of dyes in various conventional surfactants forming organized assemblies including micelles and vesicles. ${ }^{48}$ The diffusion coefficients of various dyes in a self-assembly strongly depend on the location of the dyes in that system. ${ }^{64-66}$ Here, we have used three dyes with different structural and chemical properties such as DCM (neutral dye), Rhodamine 6G (R6G) (cationic dye) and PM597 (zwitterionic dye). The diffusion coefficients of these three different probe molecules in micelles and vesicles are discussed and compared taking into account the different locations of these dyes in these systems. The preferential location of a probe molecule in a particular self-assembly strongly depends on the nature of the probe as well as the surface charge of the self-assembly. The preferential location of the dyes in micelles and vesicles of different constituting components have been discussed in light of our additional experimental evidence.

In aqueous solution, the translational diffusion coefficients $\left(D_{\mathrm{t}}\right)$ of those dyes are found to be almost similar. The measured diffusion coefficients for R6G, DCM, and PM597 are 426, 387, and $369 \mu \mathrm{m}^{2} \mathrm{~s}^{-1}$, 

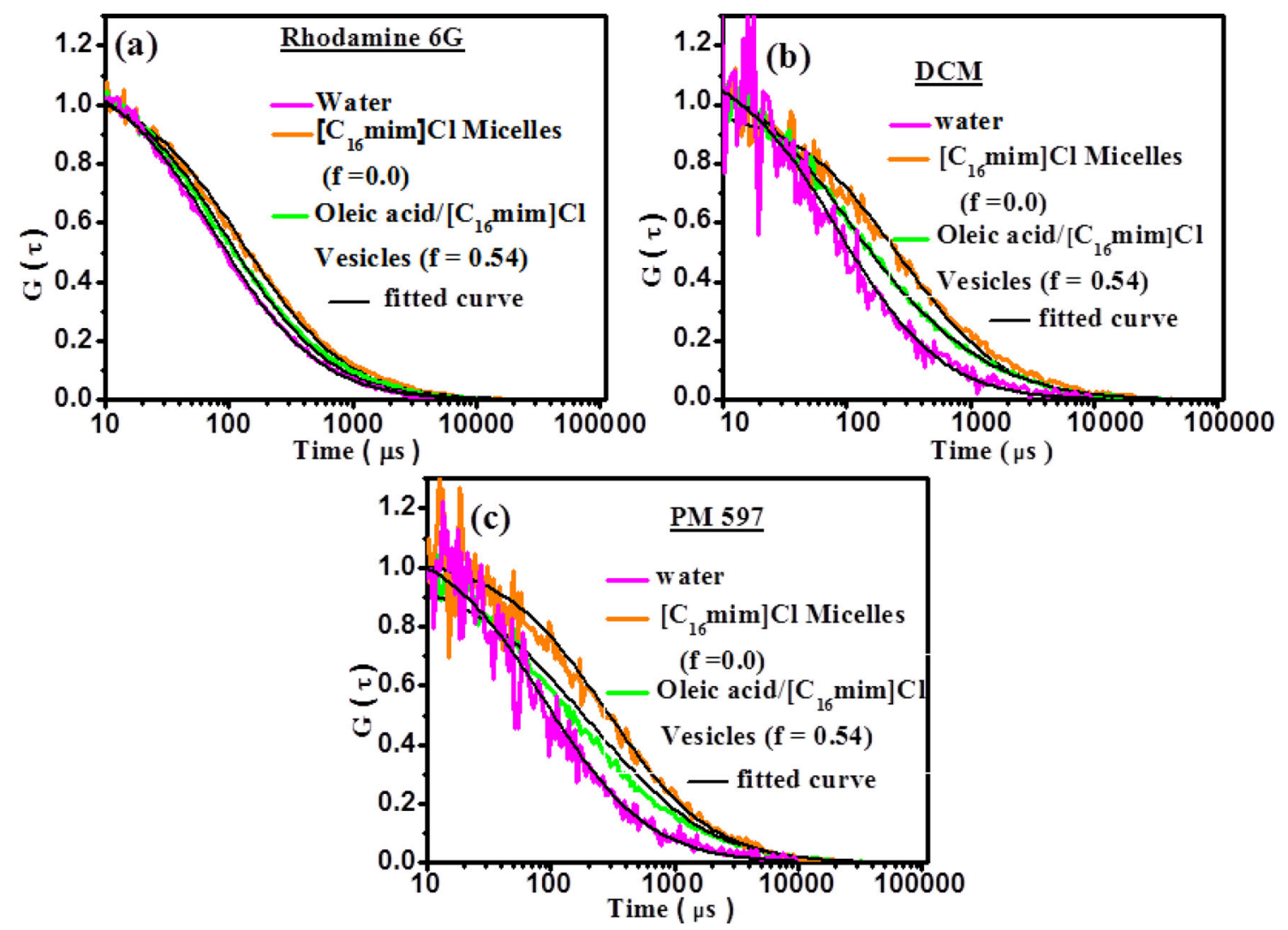

Figure 8. Fluorescence auto-correlation curves of (a) R6G, (b) DCM, and (c) PM597 in water, $\left[\mathrm{C}_{16} \mathrm{mim}\right] \mathrm{Cl}$ micelles and oleic acid/[ $\left.\mathrm{C}_{16} \mathrm{mim}\right] \mathrm{Cl}$ vesicles $(f=0.54)$.

respectively. This is also supported by the earlier literature reports. ${ }^{48}$ The FCS traces of the dyes in water, $\left[\mathrm{C}_{16} \mathrm{mim}\right] \mathrm{Cl}$ micelles $(f=0)$, and oleic acid $/\left[\mathrm{C}_{16} \mathrm{mim}\right] \mathrm{Cl}$ vesicles $(f=0.54)$ are shown in Figure 8 . The calculated diffusion coefficients of the dyes in these systems are given in Table 1 . As the $\left[\mathrm{C}_{16} \mathrm{mim}\right] \mathrm{Cl}$ micelles are spherical and almost uniformly distributed with a low polydispersity index, the FCS traces of this micellar system are fitted using single species fitting equation. From the fitted values, we can notice that the diffusion coefficients of the dyes in this micellar system are significantly lower compared to that in pure water. It indicates a hindered translational diffusion of the dyes in the $\left[\mathrm{C}_{16} \mathrm{mim}\right] \mathrm{Cl}$ micellar system. The calculated diffusion coefficients $\left(D_{t}\right)$ of R6G, DCM and PM597 encapsulated in the imidazolium-based SAIL forming cationic

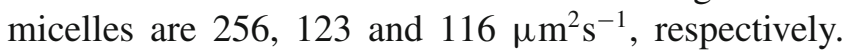
Among the three different probe molecules, a faster diffusional motion of $\mathrm{R} 6 \mathrm{G}$ in $\left[\mathrm{C}_{16} \mathrm{mim}\right] \mathrm{Cl}$ micelles is observed. This can be explained by the fact that both $\mathrm{R} 6 \mathrm{G}$ and $\left[\mathrm{C}_{16} \mathrm{mim}\right] \mathrm{Cl}$ micelles are cationic in nature and thus they experience a loose binding due to repulsive interaction causing a lesser diffusional hindrance to the dye molecules. On the other hand, DCM being a neutral dye does not get affected by the cationic surface charge of the micelles. Rather, it prefers to reside at the core of the micelles due to its hydrophobicity and poor aqueous solubility. Thus, the diffusion coefficient of DCM in the SAIL micellar solution is decreased significantly compared to R6G. This is further supported from the fact that our calculated diffusion coefficient of $\mathrm{DCM}$ in cationic $\left[\mathrm{C}_{16} \mathrm{mim}\right] \mathrm{Cl}$ micelles closely matches with the diffusion coefficient of this dye in anionic SDS micelles $\left(100 \mu \mathrm{m}^{2} \mathrm{~s}^{-1}\right)$ and in common cationic micelles of DTAB. ${ }^{48}$ In the case of the zwitterionic dye PM597 also, the diffusion coefficient is significantly decreased in the SAIL solution compared to pure water.

Addition of oleic acid into the aqueous micellar solution of $\left[\mathrm{C}_{16} \mathrm{mim}\right] \mathrm{Cl}$ resulted in the formation of large unilamellar vesicles with high polydispersity as observed from DLS and FLIM measurements. Therefore, in the vesicular assemblies, the FCS traces are fitted to a multispecies fitting equation. The calculated diffusion coefficients as obtained from the fitted results are given in Table 1. Generally, with the micellevesicle transition, the diffusion of the dyes is expected to be slowed down if the dyes strongly bind with the large-sized vesicles. Dey et al., also observed slower 
Table 1. Diffusion coefficients $\left(D_{\mathrm{t}}\right)$ of the dyes in aqueous oleic acid $/\left[\mathrm{C}_{16} \mathrm{mim}\right] \mathrm{Cl}$ systems of a different molar fraction of oleic acid ( $f=0$ and 0.54$)$ and with varying $\mathrm{pH}$ of the oleic acid $/\left[\mathrm{C}_{16} \mathrm{mim}\right] \mathrm{Cl}$ vesicle system $(f=0.54)$.

\begin{tabular}{|c|c|c|c|}
\hline \multirow[b]{2}{*}{ System } & \multicolumn{3}{|c|}{$D_{\mathrm{t}}\left(\mu \mathrm{m}^{2} / \mathrm{s}\right)^{a}$ of the dyes } \\
\hline & R6G & DCM & PM597 \\
\hline Water & $426(100 \%)$ & $387(100 \%)$ & $369(100 \%)$ \\
\hline$\left[\mathrm{C}_{16} \mathrm{mim}\right] \mathrm{Cl}$ Micelles $(f=0.0)$ & $256(100 \%)$ & $123(100 \%)$ & $116(100 \%)$ \\
\hline $\begin{array}{l}\text { Oleic acid } /\left[\mathrm{C}_{16} \mathrm{mim}\right] \mathrm{Cl} \text { Vesicles } \\
(f=0.54)(\mathrm{pH}=2.50)\end{array}$ & $343(100 \%)$ & $32(17 \%), 351(83 \%)$ & $70(48 \%), 345(52 \%)$ \\
\hline $\begin{array}{l}\text { Oleic acid } /\left[\mathrm{C}_{16} \mathrm{mim}\right] \mathrm{Cl} \text { Vesicles } \\
(f=0.54)(\mathrm{pH}=8.11)\end{array}$ & $87(41 \%), 391(59 \%)$ & $30(35 \%), 351(65 \%)$ & $69(58 \%), 345(42 \%)$ \\
\hline $\begin{array}{l}\text { Oleic acid } /\left[\mathrm{C}_{16} \operatorname{mim}\right] \mathrm{Cl} \text { Vesicles } \\
(f=0.54)(\mathrm{pH}=11.05)\end{array}$ & $85(62 \%), 347(38 \%)$ & $29(43 \%), 351(57 \%)$ & $69(56 \%), 345(44 \%)$ \\
\hline
\end{tabular}

${ }^{a}$ Experimental error $\pm 5 \%$.

diffusion of various dyes in cationic vesicles than in micelles. ${ }^{48}$ However, in the oleic acid $/\left[\mathrm{C}_{16} \mathrm{mim}\right] \mathrm{Cl}$ vesicle system, all the three dyes have a faster diffusion component as compared to the $\left[\mathrm{C}_{16} \mathrm{mim}\right] \mathrm{Cl}$ micellar solution. This indicates that these probe molecules are not strongly bound to the large unilamellar vesicles of oleic acid/ $\left[\mathrm{C}_{16} \mathrm{mim}\right] \mathrm{Cl}$ system. The diffusion coefficient of $\mathrm{R} 6 \mathrm{G}$ in oleic acid/ $\left[\mathrm{C}_{16} \mathrm{mim}\right] \mathrm{Cl}$ solution closely matches with the diffusion coefficient in pure water and fitted with a single species FCS equation. One of the reasons for the faster diffusion of dyes in vesicles than in micelles in the present system can be the dynamic nature of the large unilamellar vesicles and their interconversion to small unilamellar vesicles. In the case of DCM and PM597 also a faster diffusion component is observed that closely matches with their $D_{t}$ values in pure water and that may come from the dye molecules present in the aqueous medium. But in both the cases, a slower component is also obtained. In the case of DCM, the diffusion coefficient value of the slower component is much slower than that of PM597. This result indicates that there is an interaction between the oleic acid/SAIL vesicles and these two probe molecules. It is expected that the hydrophobic DCM molecules will prefer to reside in the bilayer of vesicles due to hydrophobic interaction and thus causing hindered diffusion of the dye molecules. On the other side, there is a possibility of electrostatic interaction between the anionic counterpart of the dye PM597 with the cationic head group of SAIL in the vesicle system and thus results in a slower diffusion of the dye molecules. The faster translational diffusion upon the micelle-vesicle transition in oleic acid/ $\left[\mathrm{C}_{16} \mathrm{mim}\right] \mathrm{Cl}$ system can also be expected from the minute change in the steady-state emission spectra of the probe molecules embedded into the system (Figure S6, Supplementary Information). From the fluorescence spectra, it is observed that upon micelle to vesicle transition the emission maxima shows a little blue shift which can be attributed to the fact that dyes are experiencing more hydrophobicity in oleic acid $/\left[\mathrm{C}_{16} \mathrm{mim}\right] \mathrm{Cl}$ vesicles as compared to $\left[\mathrm{C}_{16} \mathrm{mim}\right] \mathrm{Cl}$ micelles. But the intensities of the emission spectra are observed to decrease from micellar to the vesicular solution. So, it can be expected that the binding interaction between the dyes and the fatty acid/SAIL vesicles is much weaker than that with the SAIL micelles and also a reasonable proportion of dyes are free in the vesicular solution, and the faster diffusion coefficient in vesicular solution is coming from these loosely bound dyes. Thus, it shows that the translational diffusion behavior of the three dyes greatly depends on their location and how it varies from SAIL micelle to oleic acid/SAIL vesicle system.

3.2b Effect of $p H$ on the oleic acid $/\left[C_{16}\right.$ mim $] \mathrm{Cl}$ vesicle: In this section, we have discussed the diffusion properties of the three dyes on varying the $\mathrm{pH}$ of the oleic acid $/\left[\mathrm{C}_{16} \mathrm{mim}\right] \mathrm{Cl}$ vesicle $(f=0.54)$ system. We mentioned previously that oleic acid/ $\left[\mathrm{C}_{16} \mathrm{mim}\right] \mathrm{Cl}$ system has stability in a broad range of $\mathrm{pH}$. FCS traces of R6G, DCM and PM597 in three different pH of the oleic acid $/\left[\mathrm{C}_{16} \mathrm{mim}\right] \mathrm{Cl}$ vesicle system are shown in Figure S7 (Supplementary Information) and the diffusion coefficient data obtained from the FCS are given in Table 1. We observed earlier that with increasing the $\mathrm{pH}$ of the solution, the heterogeneity in the medium increases and larger vesicles are formed. So, we have fitted the FCS traces using multiple species fitting equation. With increasing $\mathrm{pH}$, a slower diffusion component arrived in case of R6G which is much slower as compared to its $D_{t}$ value in the water. However, in the case of DCM and PM597, the change in the diffusion coefficient values with varying the $\mathrm{pH}$ is negligible.

With increasing $\mathrm{pH}$ of the solution, oleic acid molecules become deprotonated and strongly bind to the cationic SAIL. As R6G is cationic in nature, it preferably binds to negatively charged oleate and thus results in a 
slower diffusion component and the faster component arrives due to loose binding of the dye molecules with the vesicles. Umakoshi et al., have modified the oleic acid/oleate vesicle with the addition of a cationic surfactant, Didecyldimethylammonium bromide (DDAB) and they have shown that the fluidity of the external membrane of the fatty acid vesicle is slightly affected with the addition DDAB and that correlates well with our FCS results. ${ }^{62} \mathrm{DCM}$ is expected to be present in the bilayer region of the vesicles. The dielectric dispersion analysis (DDA) of fatty acid vesicles shows that the $\mathrm{DDAB} /$ fatty acid vesicles are tightly packed with the help of electrostatic interaction between the head groups and due this interaction the membrane fluidity of these vesicles is decreased than that of pure fatty acid vesicles. ${ }^{62}$ With increasing $\mathrm{pH}$ of the system, the slower component of DCM is decreased slightly (from $32 \mu \mathrm{m}^{2} \mathrm{~s}^{-1}$ to $29 \mu \mathrm{m}^{2} \mathrm{~s}^{-1}$ ), but the contribution of the slower component is increased significantly (from $17 \%$ to $43 \%$ ) and that clearly indicates the decrease in the fluidity of the membrane. In the case of PM597, there is almost no change in the value of the diffusion coefficient but the contribution of the slower component changes a little bit. This is probably due to the repulsive interaction between the negative counterpart of the zwitterionic probe PM597 and the carboxylate group of the oleate in higher $\mathrm{pH}$.

\section{Conclusions}

We have successfully demonstrated the spontaneous formation of large unilamellar vesicles of oleic acid in the aqueous medium in presence of an imidazoliumbased surface active ionic liquid $\left[\mathrm{C}_{16} \mathrm{mim}\right] \mathrm{Cl}$. These vesicles show modified properties as compared to pure fatty acid vesicles and that is proved by our studies. We have observed that these oleic acid/SAIL vesicles are stable towards a broad range of $\mathrm{pH}$ variation $(\mathrm{pH}$ 2-11.2), whereas pure oleic acid vesicles are stable in a certain range of $\mathrm{pH}$ ( $\mathrm{pH} 7.8-9)$. We have also studied the fusion of the oleic acid $/\left[\mathrm{C}_{16} \mathrm{mim}\right] \mathrm{Cl}$ vesicles in presence of a very low concentration of $\mathrm{NaCl}$ solution using FLIM technique and the time scan confocal images clearly prove the fusion process. Apart from the detailed characterization using DLS, TEM and FLIM measurements, the organization and the dynamic behavior of the newly developed oleic acid/[ $\left.\mathrm{C}_{16} \mathrm{mim}\right] \mathrm{Cl}$ self-assemblies have been investigated using three different probe molecules, Rhodamine 6G, DCM and PM597 by using FCS technique. We have found how the diffusion properties of these three dyes encapsulated in different locations of the oleic acid $/\left[\mathrm{C}_{16} \mathrm{mim}\right] \mathrm{Cl}$ self-assemblies varies with the micelle-vesicle transition and also with varying the
$\mathrm{pH}$ of the medium. The spontaneous micelle-vesicle transition resulted in the increase in diffusional motion with higher diffusion coefficient values of the dyes in vesicles than in micelles. Finally, we conclude with a note that this newly formed ionic liquid containing fatty acid vesicles with modified properties and improved stability can be used in biological applications as potent drug carriers such as for the treatment of topical fungal infections ${ }^{67,68}$ and also as a model protocell membrane for further understanding of the emergence of life forms.

\section{Supplementary Information (SI)}

The details of the instruments used in the experimental section like steady-state fluorescence measurement, DLS, TEM, AFM, zeta potential measurement, FCS and FLIM are given in the supplementary information. Time-dependent DLS and confocal images (Figures S1-S2), DLS histograms of DMPC and oleic acid vesicles in presence of $\mathrm{NaCl}$ solution (Figure S3), cryo-TEM images of oleic acid/[ $\left.\mathrm{C}_{16} \mathrm{mim}\right] \mathrm{Cl}$ vesicles (Figure S4), zeta potential measurement of vesicles in presence of $\mathrm{NaCl}$ solution (Figure S5), steady-state fluorescence spectra and FCS traces of different dyes in oleic acid/[C $\left.{ }_{16} \mathrm{mim}\right] \mathrm{Cl}$ self-assemblies (Figures S6 and S7), and a video of fusion of oleic acid/[ $\left.\mathrm{C}_{16} \mathrm{mim}\right] \mathrm{Cl}$ vesicles in the presence of $\mathrm{NaCl}$ solution (Movie S1) are given in the Supplementary Information. Supplementary Information is available at www.ias.ac.in/chemsci.

\section{Acknowledgements}

N.S. gratefully acknowledges SERB, Department of Science and Technology (DST), Government of India for providing a generous research grant. S.R., S.M. and P. B. are thankful to UGC and CSIR for research fellowships. We are thankful to Dr. Niloy Kundu and Dr. Arpita Roy for helpful discussions.

\section{References}

1. Tang T-Y D, Che Hak, C R, Thompson A J, Kuimova M K, Williams D S, Perriman A W and Mann S 2014 Fatty Acid Membrane Assembly on Coacervate Microdroplets As a Step Towards a Hybrid Protocell Model Nat. Chem. 6527

2. Chen I A and Szostak J W 2004 Membrane Growth can Generate a Transmembrane $\mathrm{pH}$ Gradient in Fatty Acid Vesicles Proc. Natl. Acad. Sci. U.S.A. 1017965

3. Morigaki K and Szostak W 2007 Fatty Acid Vesicles Curr. Opin. Colloid Interface Sci. 1275

4. Stano P and Luisi L 2010 Achievements and Open Questions in the Self-Reproduction of Vesicles and Synthetic Minimal Cells Chem. Commun. 463639

5. Szostak J W, Bartel D P and Luisi P L 2001 Synthesizing Life Nature 409387

6. Mansy S S and Szostak J W 2008 Thermostability of Model Protocell Membranes Proc. Natl. Acad. Sci. U.S.A. 10513351 
7. Hanczyc M M, Fujikawa S M and Szostak J W 2003 Experimental Models of Primitive Cellular Compartments: Encapsulation, Growth, and Division Science 302 618

8. Walde P and Ichikawa S 2001 Enzymes inside Lipid Vesicles: Preparation, Reactivity and Applications Biomol. Eng. 18143

9. Walde P, Wick R, Fresta M, Mangone A and Luisi P L 1994 Autopoietic Self-Reproduction of Fatty Acid Vesicles J. Am. Chem. Soc. 11611649

10. Stano P, Wehrli E and Luisi P L 2006 Insights on the Oleate Vesicles Self-Reproduction J. Phys. Condens. Matter 18 S2231

11. Chen I A and Szostak J W 2004 A Kinetic Study of the Growth of Fatty Acid Vesicles Biophys. 87 988

12. Cistola D P, Hamilton J A, Jackson D and Small D M 1988 Ionization and Phase Behavior of Fatty Acids in Water: Application of the Gibbs Phase Rule Biochemistry 271881

13. Apel C L, Deamer D W and Mautner M N 2002 Self-Assembled Vesicles of Monocarboxylic Acids and Alcohols: Conditions for Stability and for the Encapsulation of Biopolymers Biochim. Biophys. Acta Biomembr. 15591

14. Markvoort A, Pfleger N, Staffhorst R, Hillbers P, Santen $\mathrm{R}$ ven, Killian J and Kruijff B de 2010 Electron Spin Resonance Study of the $\mathrm{pH}$-Induced Transformation of Micelles to Vesicles in an Aqueous Oleic Acid/Oleate System Biophys. J. 991520

15. Morigaki K and Walde P 2002 Giant Vesicle Formation from Oleic Acid/Sodium Oleate on Glass Surfaces Induced by Adsorbed Hydrocarbon Molecules Langmuir 1810509

16. Dejanović B, Noethig-Laslo V, Šentjurc $M$ and Walde $P$ 2011 On the Surface Properties of Oleate Micelles and Oleic Acid/ Oleate Vesicles Studied by Spin Labeling Chem. Phys. Lipids 16483

17. Morrow B H, Koenig P H and Shen J K 2013 SelfAssembly and Bilayer-Micelle Transition of Fatty Acids Studied by Replica-Exchange Constant pH Molecular Dynamics Langmuir 2914823

18. Bachmann P A, Luisi P L and Lang J 1992 Physical Catalysis Driven by a Bond-Forming Thiol-Ene Reaction Nature 35757

19. Bachmann P A, Walde P, Luisi P L and Lang J 1990 SelfReplicating Reverse Micelles and Chemical Autopoiesis J. Am. Chem. Soc. 1128200

20. Kanicky J R and Shah D O 2003 Effect of Premicellar Aggregation on the pKa of Fatty Acid Soap Solutions Langmuir 192034

21. Suga K, Kondo D, Otsuka Y, Okamoto Y and Umakoshi H 2016 Characterization of Aqueous Oleic Acid/Oleate Dispersions by Fluorescent Probes and Raman Spectroscopy Langmuir 327606

22. Kamp F, Zakim D, Zhang F, Noy N and Hamilton J A 1995 Fatty Acid Flip-Flop in Phospholipid Bilayers is Extremely Fast Biochemistry 34 11928

23. Monnard P A and Deamer D W 2003 Preparation of Vesicles from Nonphospholipid Amphiphiles Methods Enzymol. 372133
24. Kuchlyan J, Kundu N and Sarkar N 2016 Ionic Liquids in Microemulsions: Formulation and Characterization Curr. Opin. Colloid Interface Sci. 2527

25. Pandey S, Trivedi S, Mishra S K, Pandey P S and Pandey S 2015 Effect of a Surface-Active Lonic Liquid on Calixarenes In Ionic Liquid-Based Surfactant Science: Formulation, Characterization and Applications Bidyut K Paul and Satya P Moulik (Eds.) (John Wiley \& Sons.) Ch. 9 p. 193

26. Galgano P D and El Seoud O A 2011 Surface Active Ionic Liquids: Study of the Micellar Properties of 1-(1Alkyl)-3-methylimidazolium Chlorides and Comparison With Structurally Related Surfactants J. Colloid Interface Sci. 361186

27. Gu Y, Shi L, Cheng X, Lu F and Zheng L 2013 Aggregation Behavior of 1-Dodecyl-3-methylimidazolium Bromide in Aqueous Solution: Effect of Ionic Liquids with Aromatic Anions Langmuir 296213

28. Wang H, Wang J, Zhang S B and Xuan X P 2008 Structural Effects of Anions and Cations on the Aggregation Behavior of Ionic Liquids in Aqueous Solutions J. Phys. Chem. B 11216682

29. Brown P, Butts C P, Eastoe J, Fermin D, Grillo I, Lee H, Parker D, Plana D and Richardson R M 2012 Anionic Surfactant Ionic Liquids with 1-Butyl-3-methylimidazolium Cations: Characterization and Application Langmuir 282502

30. Yuan J, Bai X, Zhao M and Zheng L $2010 \mathrm{C}_{12} \mathrm{mimBr}$ Ionic Liquid/SDS Vesicle Formation and Use As Template for the Synthesis of Hollow Silica Spheres Langmuir 2611726

31. Mandal S, Kuchlyan J, Ghosh S, Banerjee C, Kundu N, Banik D and Sarkar N 2014 Vesicles Formed in Aqueous Mixtures of Cholesterol and Imidazolium Surface Active Ionic Liquid: A Comparison with Common Cationic Surfactant by Water Dynamics J. Phys. Chem. B 1185913

32. Zettl H, Portnoy Y, Gottlieb M and Khaisch G 2005 Investigation of Micelle Formation by Fluorescence Correlation Spectroscopy J. Phys. Chem. B 10913397

33. Orte A, Ruedas-Rama M J, Paredes J M, Crovetto L and Alvarez-Pez J M 2011 Dynamics of Water-in-Oil Nanoemulsions Revealed by Fluorescence Lifetime Correlation Spectroscopy Langmuir 2712792

34. Korlach J, Schwille P, Webb W W and Feigenson G W 1999 Characterization of Lipid Bilayer Phases by Confocal Microscopy and Fluorescence Correlation Spectroscopy Proc. Natl. Acad. Sci. U.S.A. 968461

35. Benda A, Benes M, Merecek V, Lhotsky A, Hermens W Th and Hof M 2003 How To Determine Diffusion Coefficients in Planar Phospholipid Systems by Confocal Fluorescence Correlation Spectroscopy Langmuir 19 4120

36. Humpolickova J, Gielen E, Benda A, Fagulova J, Vercammen J, Vandeven M, Hof M, Ameloot M and Engelborghs Y 2006 Probing Diffusion Laws within Cellular Membranes by Z-Scan Fluorescence Correlation Spectroscopy Biophys. J. 91 L23

37. Kirkeminde A W, Torres $\mathrm{T}$, Ito $\mathrm{T}$ and Higgins $\mathrm{D}$ A 2011 Multiple Diffusion Pathways in Pluronic F127 Mesophases Revealed by Single Molecule Tracking and Fluorescence Correlation Spectroscopy J. Phys. Chem. B 11512736 
38. Patra S and Samanta A 2012 Microheterogeneity of Some Imidazolium Ionic Liquids As Revealed by Fluorescence Correlation Spectroscopy and Lifetime Studies J. Phys. Chem. B 11612275

39. Wang D, Yuan Y, Mardiyati Y, Bubeck C and Koynov K 2013 From Single Chains to Aggregates, How Conjugated Polymers Behave in Dilute Solutions Macromolecules 466217

40. Wu D and Schanze K S 2014 Protein Induced Aggregation of Conjugated Polyelectrolytes Probed with Fluorescence Correlation Spectroscopy: Application to Protein Identification ACS Appl. Mater. Interfaces 6 7643

41. Sahoo B, Balaji J, Nag S, Kaushalya K and Maiti S 2008 Protein Aggregation Probed by Two-Photon Fluorescence Correlation Spectroscopy of Native Tryptophan J. Chem. Phys. 129075103

42. Pal N, Verma S D, Singh M K and Sen S 2011 Fluorescence Correlation Spectroscopy: an Efficient Tool for Measuring Size, Size-Distribution and Polydispersity of Microemulsion Droplets in Solution Anal. Chem. 83 7736

43. Müller C B, Loman A, Richtering W and Enderlein J 2008 Dual-Focus Fluorescence Correlation Spectroscopy of Colloidal Solutions: Influence of Particle Size J. Phys. Chem. B 1128236

44. Ishii K and Tahara T 2013 Two-Dimensional Fluorescence Lifetime Correlation Spectroscopy. 2. Application J. Phys. Chem. B 11711432

45. Schubert F, Zettl H, Hafner W, Krauss G and Krausch G 2003 Comparative Thermodynamic Analysis of DNAProtein Interactions Using Surface Plasmon Resonance and Fluorescence Correlation Spectroscopy Biochemistry 4210288

46. Burnett G R, Rees G D, Styetler D C and Robinson B H 2004 Fluorescence Correlation Spectroscopy of Water-in-Oil Microemulsions: an Application in Specific Characterization of Droplets Containing Biomolecules Colloids Surf. A $\mathbf{2 5 0} 171$

47. Mojumdar S S, Chowdhury R, Chattoraj S and Bhattacharyya K 2012 Role of Ionic Liquid on the Conformational Dynamics in the Native, Molten Globule, and Unfolded States of Cytochrome C: A Fluorescence Correlation Spectroscopy Study J. Phys. Chem. B 116 12189

48. Dey S, Mandal U, Mojumdar S S, Mandal A K and Bhattacharyya K 2010 Diffusion of Organic Dyes in Immobilized and Free Catanionic Vesicles J. Phys. Chem. B 11415506

49. Israelachvili J N, Mitchell D J and Ninham B W 1976 Theory of Self-Assembly of Hydrocarbon Amphiphiles into Micelles and Bilayers J. Chem. Soc., Faraday Trans. 2721525

50. Ferrer-Tasies L, Moreno-Calvo E, Cano-Sarabia M, Aguilella-Arzo M, Angelova A, Lesieur S, Ricart S, Faraudo J, Ventosa N and Veciana J 2013 Quatsomes: Vesicles Formed by Self-Assembly of Sterols and Quaternary Ammonium Surfactants Langmuir 29 6519

51. Karatekin E and Rothman J E 2012 Fusion of Single Proteoliposomes with Planar, Cushioned Bilayers in Microfluidic Flow Cells Nat. Protoc. 7903
52. Terasawa E, Nishimura $\mathrm{K}$, Suzuki $\mathrm{H}$, Matsuura $\mathrm{T}$ and Yomo T 2012 Coupling of the Fusion and Budding of Giant Phospholipid Vesicles Containing Macromolecules Proc. Natl. Acad. Sci. U.S.A. 1095942

53. Ohki S and Arnold K 2000 A Mechanism for IonInduced Lipid Vesicle Fusion Colloids Surf. B 1883

54. Kantor H L and Prestegard J H 1978 Fusion of Phosphatidylcholine Bilayer Vesicles: Role of Free Fatty Acid Biochemistry 173592

55. Henderson I M and Paxton W F 2014 Salt, Shake, FuseGiant Hybrid Polymer/Lipid Vesicles through Mechanically Activated Fusion Angew. Chem. Int. Ed. 53 3372

56. Carmona-Ribeiro A M and Chaimovich H 1986 Salt-Induced Aggregation and Fusion of Dioctadecyldimethylammonium Chloride and Sodium Dihexadecylphosphate Vesicles Biophys. J. 50621

57. Roy A, Banerjee P, Dutta R, Kundu S and Sarkar N 2016 Probing the Interaction between a DNA Nucleotide (Adenosine-5'-Monophosphate Disodium) and Surface Active Ionic Liquids by Rotational Relaxation Measurement and Fluorescence Correlation Spectroscopy Langmuir 3210946

58. Berezin M Y and Achilefu S 2010 Fluorescence Lifetime Measurements and Biological Imaging Chem. Rev. 110 2641

59. Lin H J, Herman P and Lakowicz J R 2003 Fluorescence Lifetime-Resolved $\mathrm{pH}$ Imaging of Living Cells Cytometry Part A $\mathbf{5 2} 77$

60. Setiawan I and Blanchard G J 2014 Ethanol-Induced Perturbations to Planar Lipid Bilayer Structures J. Phys. Chem. B 118537

61. Setiawan I and Blanchard G J 2014 Structural Disruption of Phospholipid Bilayers over a Range of Length Scales by n-Butanol J. Phys. Chem. B 1183085

62. Suga K, Yokoi T, Kondo D, Hayashi K, Morita S, Okamoto Y, Shimanouchi $\mathrm{T}$ and Umakoshi H 2014 Systematical Characterization of Phase Behaviors and Membrane Properties of Fatty Acid/Didecyldimethylammonium Bromide Vesicles Langmuir 3012721

63. Kundu N, Banerjee P, Kundu S, Dutta R and Sarkar N 2017 Sodium Chloride Triggered the Fusion of Vesicle Composed of Fatty Acid Modified Protic Ionic Liquid: A New Insight into the Membrane Fusion Monitored through Fluorescence Lifetime Imaging Microscopy $J$. Phys. Chem. B 12124

64. Sasmal D K, Mandal A K, Mondal T and Bhattacharyya K 2011 Diffusion of Organic Dyes in Ionic Liquid and Giant Micron Sized Ionic Liquid Mixed Micelle: Fluorescence Correlation Spectroscopy J. Phys. Chem. B 115 7781

65. Ghosh S, Adhikary A, Sen Mojumdar S and Bhattacharyya K 2010 A Fluorescence Correlation Spectroscopy Study of the Diffusion of an Organic Dye in the Gel Phase and Fluid Phase of a Single Lipid Vesicle J. Phys. Chem. B 1145736

66. Roy A, Dutta R, Banerjee P, Kundu S and Sarkar N 2016 5-Methyl Salicylic Acid-Induced Thermo Responsive Reversible Transition in Surface Active Ionic Liquid Assemblies: A Spectroscopic Approach Langmuir 32 7127 
67. Zakir F, Vaidya B, Goyal A K, Malik B and Vyas S P 2010 Development and Characterization of Oleic Acid Vesicles for the Topical Delivery of Fluconazole Drug Deliv. 17238
68. Verma S, Bharadwaj A, Vij M, Bajpai P, Goutam N and Kumar L 2013 Oleic Acid Vesicles: A New Approach for Topical Delivery of Antifungal Agent Artif. Cells Nanomed. Biotechnol. 4295 